\title{
The 'Ellis' and 'Ryrie' tests
}

\author{
B NAAFS, ${ }^{*} \mathrm{~N}$ F LYONS, $\dagger$ B O MATEMERA* \\ \& L MADOMBI \\ *National Leprosy Control Ministry of Health, P.O. Box 8204, \\ Causeway, Harare, Zimbabwe; $\dagger$ Department of Medical Micro- \\ biology, Godfrey Huggins School of Medicine; $\ddagger$ Tropical Disease \\ Unit, Harare Hospital, Zimbabwe
}

Accepted for publication 11 June 1986

Summary Two simple non-time consuming tests for the detection of reaction and
guidance of reactional therapy in leprosy patients are described and analysed. The
tests showed to be useful both in hospital and in the field.

\section{Introduction}

Leprosy would be a rather innocuous disease if it were not for the permanent disability which may follow neural damage. Such damage usually results from episodes of so called reactions, reversal reaction (RR), a cell-mediated immune reaction, occurring in borderline patients $\mathrm{s}^{1,2}$ and erythema nodosum leprosum (ENL), an immune complex reaction ${ }^{3,4}$ occurring in lepromatous patients.

When reactions are detected early and treated properly, patients will not suffer from major nerve damage.

For an experienced leprologist, it is usually not too difficult to discern that a patient is in reaction, but for less experienced field workers it is often more difficult.

When a reaction is diagnosed it is important to give the antireaction treatment in an adequate dosage for an adequate time. ${ }^{5}$ Treatment of RR is now more or less standardized ${ }^{6}$ with effective results. ${ }^{7,8}$ However for ENL, being an episodic occurrence, guidelines in therapy are more difficult to establish, especially concerning dosage and duration, as individual patients respond differently.

This paper describes and analyses results obtained using two simple tests which may help in the detection and treatment of reaction. 


\section{Material and methods}

Data from patients on the National Leprosy Register of Zimbabwe are analysed. Patients are classified clinically and bacteriologically according to the RidleyJopling classification. ${ }^{9}$

From computerized data of the initial assessment of 2356 patients data were extracted from those who were diagnosed as being in 'reaction', either RR or ENL, or who had a positive 'Ryrie' or 'Ellis' test.

Patients were considered to be in $R \mathrm{R}$ when there were active inflamed skin lesions, tender nerves or signs of recent nerve damage as detected by voluntary muscle testing $(\mathrm{VMT})^{10}$ or graded sensory testing (GST). ${ }^{11}$ Lepromatous patients were considered to suffer from ENL, when they developed painful erythematous nodules, tender nerves, lymphadenopathy or arthritis with or without fever. The 'Ryrie' test was first described by Ryrie over 40 years ago (B P B Ellis; personal communication). This test is based on the observation that patients in ENL have a tendency to walk as if on hot coals, due to the pain experienced in physical contact between ground and plantar surface of the foot.

The 'Ryrie' test is performed by passing a blunt instrument (the handle of a reflex hammer) over the plantar surface of the foot with light pressure (as in the Babinski reflex test), whilst observing the patient's face. The test is considered positive when the patient shows to experience pain by wincing.

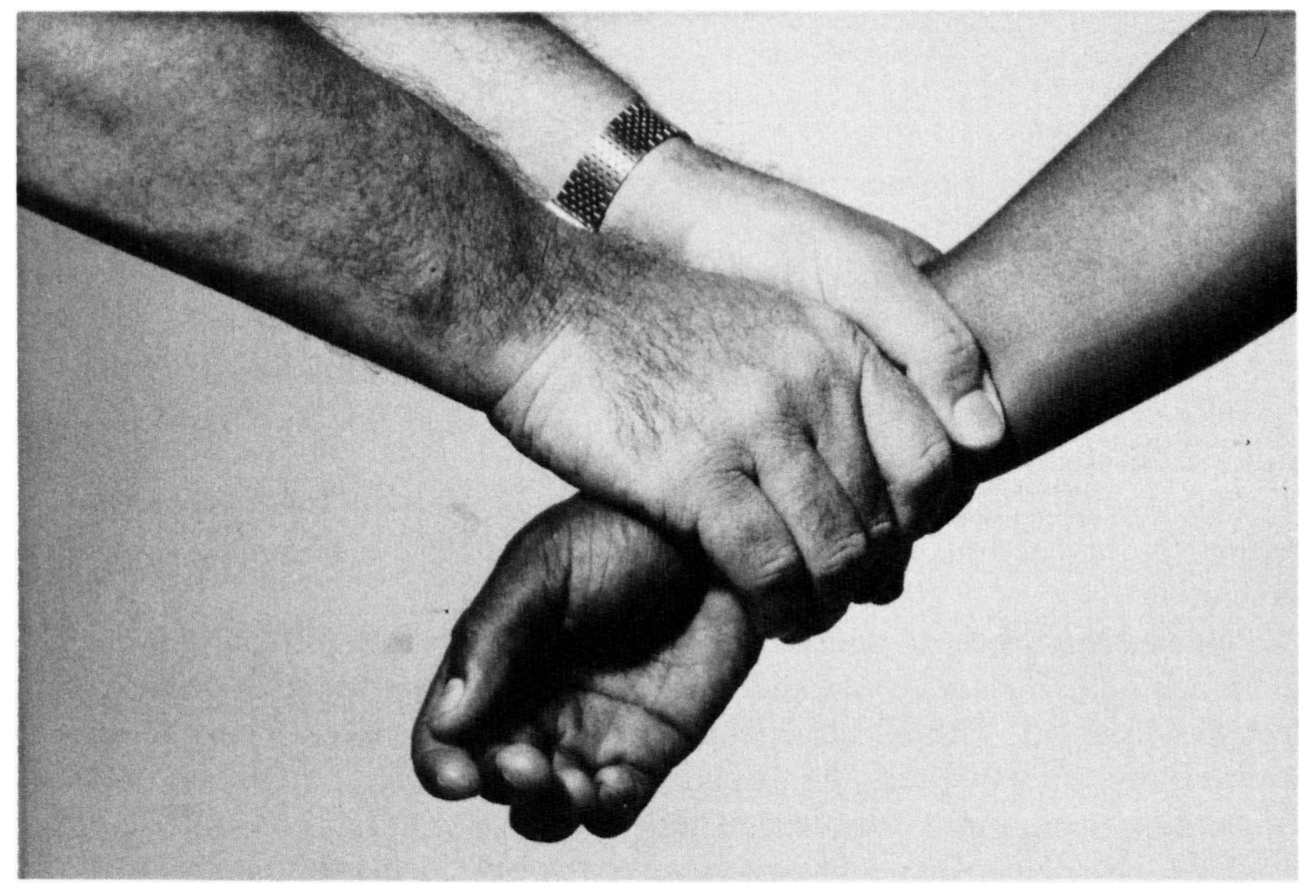

Figure 1. 'Ellis' test. 
The 'Ellis' test has been used for many years by B P B Ellis investigating leprosy patients in Zimbabwe and elsewhere. In this test the arm of the patient just above the wrist is squeezed gently with both hands as shown in Figure 1. The test is considered positive when the patient's face indicates pain.

To evaluate the efficacy of these tests a number of patients admitted for reactional treatment at the Tropical Disease Unit of the Harare Hospital were carefully followed in a longitudinal study.

The results of the 'Ellis' test were analysed to determine why it became positive, by comparing it with pinching of the skin, palpation of nerves and pressure on the periosteum.

Table 1. Number of patients in reaction, patients with positive 'Ellis' and 'Ryrie' tests grouped according to experience of the examiners.

\begin{tabular}{lcccc}
\hline & & $\begin{array}{c}\text { 'Ellis’ test } \\
\text { positive (\%) }\end{array}$ & $\begin{array}{c}\text { 'Ryrie' test } \\
\text { positive (\%) }\end{array}$ & $\begin{array}{c}\text { Detected by } \\
\text { either tests (\%) }\end{array}$ \\
Reaction (73) & 13 & 77 & 70 & 77 \\
\hline Hospital & 32 & 63 & 41 & 69 \\
Rural exp & 28 & 36 & 43 & 54 \\
Rural inexp & & & & \\
& & In reaction & $(\%)$ & \\
'Ellis' test positive(103) & & & & \\
Hospital & 11 & 10 & 91 & \\
$\quad$ Rural exp & 32 & 20 & 63 & \\
$\quad$ Rural inexp & 60 & 11 & 17 & \\
'Ryrie' positive (164) & & & & \\
$\quad$ Hospital & 9 & 9 & 100 & \\
Rural exp & 61 & 13 & 21 & \\
$\quad$ Rural inexp & 94 & 12 & 13 \\
\hline
\end{tabular}

Table 2. Results of the 'Ellis' test in relation to tender lower arm structures.

Ellis' test Tender nerves Tender periost Tender skin Nothing

\begin{tabular}{ccccc}
\hline $\begin{array}{c}\text { Positive } \\
16\end{array}$ & 9 & 4 & 10 & 4 \\
& $(56 \%)$ & $(25 \%)$ & $(62 \%)$ & $(25 \%)$ \\
$\begin{array}{c}\text { Negative } \\
5\end{array}$ & 2 & 0 & 0 & 0 \\
\hline
\end{tabular}


Table 3. A and B follow-up of 2 patients in R R. C and D follow-up of 2 patients in ENL.

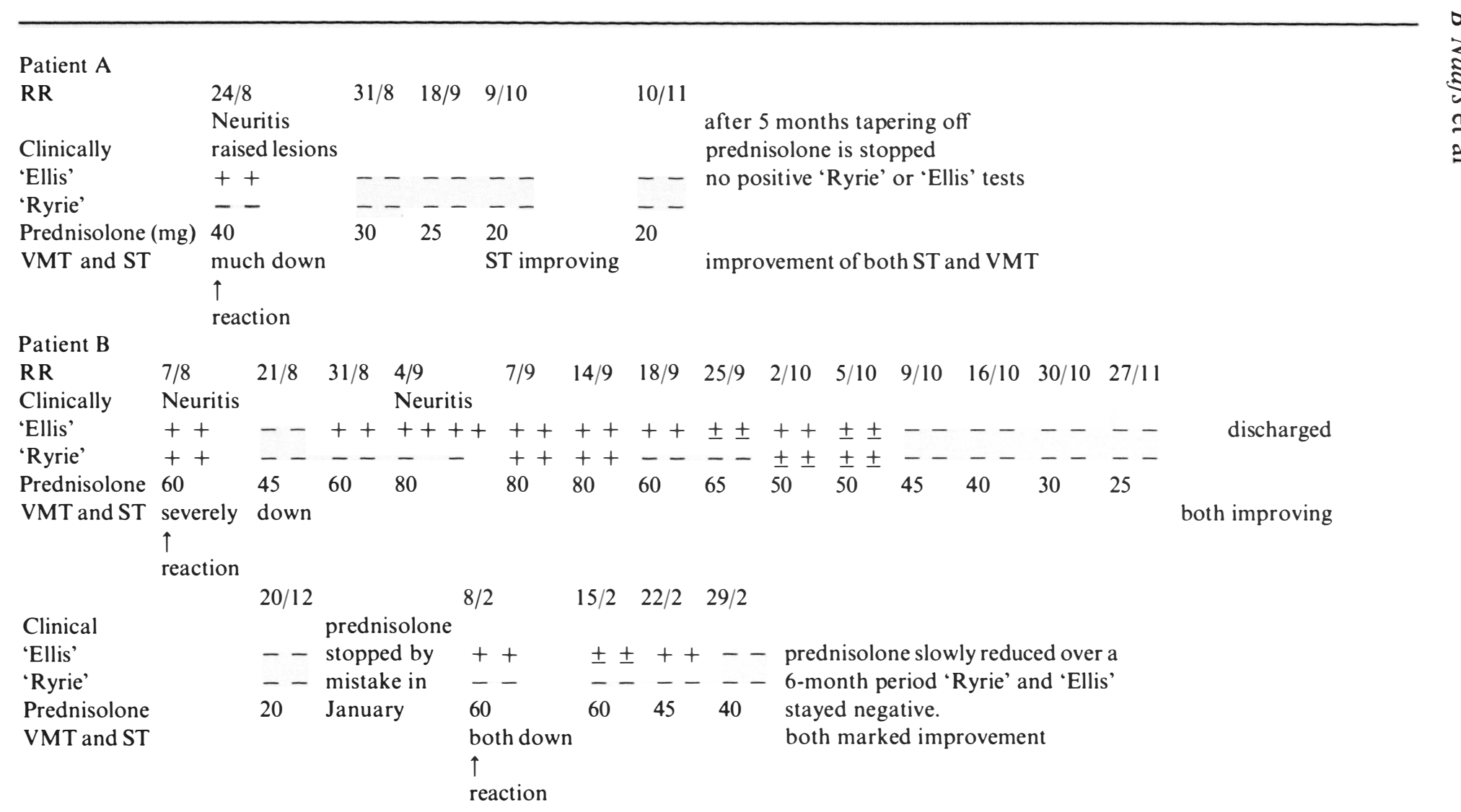


Table 3 (continued)

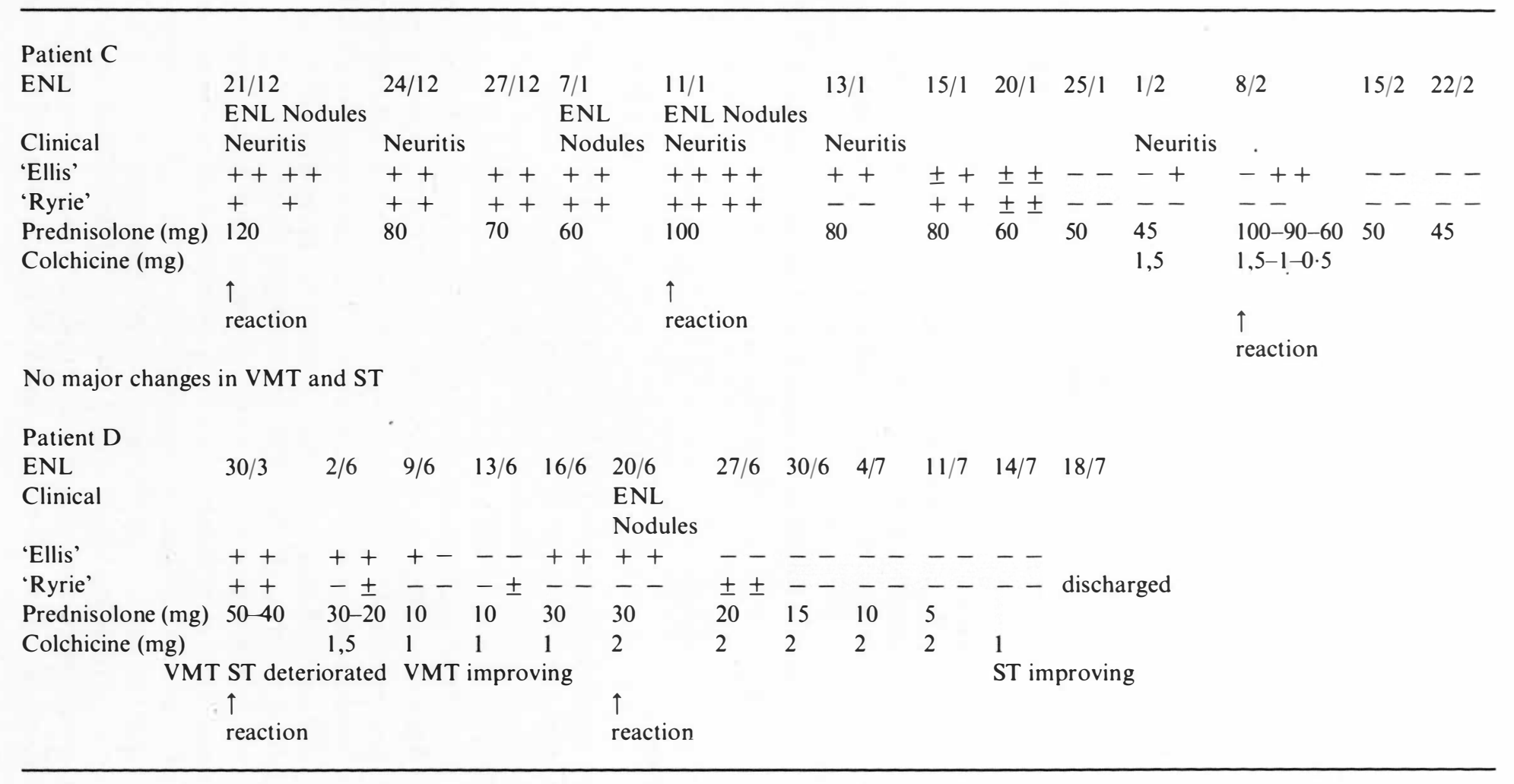




\section{Results}

Analysis of the initial assessment of 2356 patients indicated that 73 were in reaction. In 103 patients the 'Ellis' test was positive in one or both wrists and in 164 the 'Ryrie' test was positive.

Of the patients with a positive. 'Ellis' test $40(39 \%)$ were in reaction as were 34 $(21 \%)$ with a positive 'Ryrie' test.

In order to assess the influence of experience in performing these tests, the available data were analysed according to where they were performed. Comparison is made of results obtained from a hospital, provinces with experienced staff and provinces with less experienced staff (Table 1).

Table 2 analyses the 'Ellis' test performed on 11 patients admitted to hospital with a reaction. Three were suffering from a RR and 8 had ENL. In 1 patient only one wrist was assessed as an infection of a finger on the other hand could have influenced the results.

When the 'Ellis' test was positive in a patient with RR, the radiocutaneous or median nerve was found to be tender in nearly all cases. In patients with ENL more structures were found to be tender with the skin most frequently involved. In 4 wrists the 'Ellis' test was found positive, without either tender skin, periostia or nerves.

Table 3 shows the follow-up of 4 patients, 2 with ENL and 2 with RR in whom the 'Ellis' and 'Ryrie' tests were used to guide treatment.

\section{Discussion}

The low number of reactions (73) found in the initial assessment of 2356 patients, may be explained by the fact, that the majority of these patients had previously received dapsone monotherapy, before they were assessed and transferred to multiple drug therapy (MDT).

Of the 300 previously untreated patients 26 were reported to be in reaction ( 12 ENL, 9 R R and 5 unknown, but most likely also RR). This is the same percentage $( \pm 10 \%)$ as found among new patients attending the out-patients department of the All Africa Leprosy and Rehabilitation Training Centre (ALERT) in Addis Ababa, Ethiopia (9 out of 70 new borderline patients and 2 out of 16 new lepromatous patients) (Naafs 1975; unpublished observation).

In many of the patients in reaction both 'Ellis' and 'Ryrie' tests were positive. With these relatively simple tests $64 \%$ of these patients could be detected, although experience played an important role (Table 1). In a number of patients, the fact that one or both of these tests were positive made the examiner look more carefully for other signs which could show that the patient was in reaction; tender nerves, erythematous or infiltrated lesions or symptoms of recent nerve damage.

Although the specificity of these tests is high, 0.972 for the 'Ellis' test and 0.943 
for the 'Ryrie' test, the sensitivity is less, 0.54 for the 'Ellis' test only 0.46 for the 'Ryrie' test, but 0.64 for the both combined (Table 2).

In patients in reaction whose tests were negative extensive 'glove and stocking' anesthesia was often present. It is remarkable that the 'Ryrie' test was often falsely positive in patients with extensive plantar anesthesia. It is possible that in these patients the deep sensation is still intact and that its stimulation is not inhibited by 'lateral inhibition' evoked by plantar skin stimulation.

Another frequent reason for a false positive 'Ryrie' test was the observation; that inexperienced examiners frequently mistook the reaction of the patient on 'tickling' for a reaction to pain.

What actually is 'measured' in a true positive 'Ryrie' test is not clear. It is possible that during a reaction the threshold for pain stimuli is lowered, as is shown for touch stimuli" in patients with acroedema in R R.

A positive 'Ellis' test in patients in R R is usually due to the local tenderness of the radiocutaneous and/or median nerve. However, in a few patients not included in Table 2 it was found that the 'Ellis' test could be positive even in the absence of nerve tenderness.

A positive 'Ellis' test in patients in ENL could also be related to tenderness of other structures (Table 2). Although most of the patients the skin was tender, the number of patients that responded with tenderness of the periostia was unexpectedly high. This could indicate that the periosteum is more often involved in ENL than generally assumed.

In 4 wrists the 'Ellis' test was positive despite non-tenderness of nerves, skin or periostia. This could be due to a general lower threshold for pain stimuli, or the involvement of other structures; myositis, tendovaginitis, with involvement of the synovia of the tendon sheats. ${ }^{12}$

False positive 'Ellis' tests were often found to be due to excessive pressure on squeezing of the wrist by inexperienced examiners.

In Table 3 it can be seen that in RR 'Ellis' and 'Ryrie' tests rapidly become and stay negative after instigation of antireactional therapy. Provided this treatment follows the recommendations of Naafs et al. ${ }^{5}$ and the suppression of cellmediated immunity lasts long enough to prevent a recrudescence of the reaction. This was not the case in patient B in whom the prednisolone was stopped too early. In the same patient there were some problems in determining the right start dose of prednisolone.

In ENL, the tests showed to be of great value, often being positive before other clinical signs, including ENL nodules or nerve tenderness appeared.

In our opinion these simple, non-time consuming tests showed to be a valuable addition to the common routine investigations in detecting patients in reaction, especially for the less experienced examiners in the field.

Both tests showed to be of value in determining the dosage of antireactional treatment especially in patients with ENL, experiencing episodic reactional periods. 


\section{Acknowledgment}

The Zimbabwe National Programme is financed by the Zimbabwe Government and ILEP. The Associazione Italiana Amici di Raoul Follereau is the ILEP coordinator.

We thank Mr B P B Ellis for introducing us to the 'Ryrie' and 'wrist' test.

\section{References}

I Godal T, Myrvang B, Samuel DR, Ross WF, Løfgren M. Mechanisms of 'reaction' in borderline tuberculoid (BT) leprosy. Acta Path. Microbiol. Sc. Sect A Suppl 1973; 236: 45-53.

2 Bjune G, Barnetson R StC, Ridley DS, Kronvall G. Lymphocyte transformation test in leprosy: correlation of the response with inflammation of lesions. Clin exp Imm, 1976; 25: 85-90.

${ }^{3}$ Bjørvatn B, Barnetson R StC, Kronvall G, Zubler RH, Lambert PH. Immune complexes and complement hypercatabolism in patients with leprosy. Clin exp Imm, 1976; 26: 388-96.

${ }^{4}$ Ridley MJ, Ridley DS. The immunopathology of erythema nodosum leprosum: the role of extravacular complexes. Lepr Rev, 1983; 54: 95-108.

5 Naafs B, Pearson JMH, Wheate HW. Reversal reaction: prevention of permanent nerve damage. Comparison of short- and long-term steroid treatment. Int J Lepr, 1979; 47: 7-12.

${ }^{6}$ Naafs B. Therapy of neuritis during reaction in leprosy. Quaderni di cooperazione sanitariaHealth cooperation papers. 1981; 65-70.

7 Touw-Langendijk EMJ, Brandsma JW, Andersen JG. Treatment of ulnar and median nerve function loss in borderline leprosy. Lepr Rev, 1984; 55: 41-6.

${ }^{8}$ Kiran KU, Stanley JNA, Pearson JMH. The outpatients treatment of nerve damage in patients with borderline leprosy using a semi-standardised steroid regimen. Lepr Rev, 1985; 56: 127-34.

${ }^{9}$ Ridley DS, Jopling WH. Classification of leprosy according to immunity. Int J Lepr, 1966; 34: 255-70.

${ }^{10}$ Brandsma JW. Basic nerve function assessment in leprosy patients. Lepr Rev, 1981; 52: 161-71.

1 Naafs B, Dagne T. Sensory Testing: A sensitive method in the follow-up of nerve involvement. Int J Lepr, 1977; 45: 364-8.

12 Malaviya GN, Ramu G, Mukherjee A, Hussain S, Ramanathan VD. Synovial swellings over wrist in leprosy. Ind J Lepr, 1985; 57: 350-3. 